\title{
The Importance of Predictive and Face Validity in Employee Selection and Ways of Maximizing Them: An Assessment of Three Selection Methods
}

\author{
Kelechi John Ekuma ${ }^{1}$ \\ ${ }^{1}$ School of Environment and Development, University of Manchester, Manchester, United Kingdom \\ Correspondence: Kelechi John Ekuma, Institute for Development Policy and Management (IDPM), School of \\ Environment and Development, University of Manchester, Manchester, United Kingdom. Tel: 44-753-844-5734. \\ E-mail: keccent@hotmail.co.uk
}

Received: May 27, 2012 Accepted: September 25, 2012 Online Published: October 29, 2012

doi:10.5539/ijbm.v7n22p115 URL: http://dx.doi.org/10.5539/ijbm.v7n22p115

\begin{abstract}
The current exigencies and fluidity of the business environment engendered largely by demographic changes, technological advances and globalisation have made it imperative for organisations to posses the brightest talents as a source of competitive advantage, if they hope to survive. The continuing 'talent war' and fierce competition in the global market place; and issues concerning employee branding and candidate attraction, means that organisations and their managers have to carefully review their recruitment and selection processes, ensuring that employee selection methods not only contributes towards enhancing organisational image, but also predicts future job performance to a reasonable extent. There is therefore, the need for chosen methods to be high in both Predictive and Face validities.

This article critically examines the importance of the concepts of Predictive and Face validities to employee selection in a wider context as an HR strategy and as an integral part of organisations' general strategy, suggesting ways of improving both concepts. The central argument of this article, is that for selection methods to be effective, reliable, valid and minimise costs associated with loosing top talents, poor employee performance and turnover, it must possess high predictive and face value. The article assesses three major selection methods (interviews, work sampling and assessment centres) with a view of maximising their predictive and face validities, arguing that the design, contents and the manner of administrating these methods are major issues. The paper concludes that there is no one best way of selecting new employees, but a combination of carefully chosen methods and well-trained HR professionals will undoubtedly improve face and predictive validities and by extension, the selection method.
\end{abstract}

Keywords: predictive validity, face validity, employee selection, employee branding, interviews, work sampling, assessment centres

\section{Introduction}

The effective acquisition and utilization of an organisation's human resources is central to the growth, viability and survival of any organisation (Jones \& George, 2006). Employee selection as an aspect of human resourcing, in a wider context of human resource management (HRM) 'is the process by which managers and others use specific instruments to choose from a pool of applicants a person or persons more likely to succeed in the job(s), given the management goals and legal requirements' (French \& Rumbles, 2009: 141).

The concepts of predictive and face validity have been identified as critical to employee-selection. Although without a univocal definition, a critical evaluation of many of the definitions offered by various scholars, point to the fact that face validity has to do with how applicants perceive, accept and react to a selection process; while predictive validity centres on how the process is able to correctly measure or predict the future job performance of those selected (Pilbeam \& Corbridge, 2006; Smither et al, 1993; Ni \& Hauenstein, 1998; French \& Rumbles, 2009).

Considering the centrality of employee selection to the functioning of organizations, this paper critically examines the importance of 'predictive' and 'face' validities to employee selection, with a view of highlighting procedures for maximising its utility and efficacy. It argues that both concepts are mutually reinforcing and that 
for any selection method to be effective, valid and reliable, it must be high on both measures. The paper also highlights the fact that there is empirical evidence (e.g. Smither et al, 1993) to suggest that some selection procedures with astonishingly high face value, have been found wanting in terms of its predictive usefulness and vice versa. While not pretending to have any 'best practice' paradigm, it concludes by offering holistic and workable suggestions based on contingency and organisational context on how organisations can maximise the efficacy of both concepts in the selection process as part of an effective human resourcing strategy.

\section{The Importance of Predictive and Face Validity in Employee Selection: A Critical Assessment}

Organisations need to attract and retain the best hands, if they hope to survive in the contemporary global market place. Moreover, the costs (both implicit and direct) associated with hiring; especially when the process goes wrong is becoming astronomically higher by the day (CIPD, 2007). The importance of predictive and face validity to employee-selection can therefore be subsumed in the above premise and forms the basis of our analysis.

While recognising that both concepts are intrinsically interwoven, they will be treated separately in this section of the paper to ensure lucidity.

\subsection{Face Validity}

The importance of face validity in employee-selection is wide-ranging and cannot be overemphasised. First, in line with the Employer Branding Theory, which centres on the public image an organisation projects through its policies and activities, is the need to attract potential employees to the organisation (CIPD, 2009). This need has been further heightened by the current demographics of the labour market. The acute skills shortages currently being experienced by many industrialised countries of the world, including the United Kingdom (U.K) has made it imperative for organisation to remain attractive to attract the best talents. Corroborating this view, Hausknecht et al (2004) relying on the Attraction theory, assert that it is of significant importance for organisations to maintain a positive image during the selection process as there are costs associated with loosing top candidates. Applicants who find particular aspects of the selection system invasive may view the company as a less attractive option in the job search process (Hausknecht et al., 2004: 3). Labour shortages have led to what many analysts have since characterised the 'war for talent'. Organisational attractiveness is therefore important because as the 'war' intensifies, 'organisations that maintain their attractiveness throughout the recruiting and selection process will definitely have an advantage' (Smither et al., 1993: 50).

Furthermore, consistent with Rynes' (1993) model of signalling theory, in the context of selection, is the fact that candidates usually interpret the selection process as signals of an organisation's characteristics; as a form of a realistic job preview and informs the candidate's choice to join the organisation or not, even if an offer was made (Hausknecht et al., 2004). This invariably conditions their perception of the organisation and forms the basis of the psychological contract if hired (Allen et al, 2007). For the same reason, there might be possible 'spill over' effects, like refusal to buy the company's product and discouraging others from doing so as well (Rynes, 1990).

In the same vein, face validity and applicants' perception of fairness directly influence subsequent attitudes and behaviours towards the organisation (Rynes, 1990). Indeed, the idea has been conceptually linked with additional outcomes including job satisfaction, organisational commitment, turnover and organisational climate (Gilliland, 1993). This has the potentiality of reducing the actual predictive value or utility of a selection process. Further, as $\mathrm{Ni}$ and Hauenstein (2004) have pointed out, because intentions and behaviours tend to be moderately related, applicants perceptions of a selection process should be related to actual behaviours such as recommending the employer to others, reapplying, retesting, and bringing litigations claims (Hausknecht et al., 2004).

From the foregoing therefore, it is plausible to conclude that as a critical concept in recruitment and selection, the underlying importance of face validity, is that it gives an insight to applicants' reaction to a particular selection method and their attitudes towards the organisation thereafter. As recruiters, understanding when and why applicants have more or less favourable impressions of a selection process might increase the ability to influence those perceptions and its associated behaviours (Smither et al., 2004).

\subsection{Predictive Validity}

The central concern of any selection method is to pick out the best candidates in order to maximise the utility and predictability of the process. If an organisation is to achieve a competitive advantage in this contemporary market place, it is important that those hired from the selection process should provide maximum utility and productivity on their various assigned tasks (Allan et al., 2007). As Pilbeam and Corbridge (2006: 142) have pointed out, 'inappropriate selection decisions reduce organisational effectiveness, invalidate reward and development strategies, are frequently unfair on individuals recruited and can be distressing for managers who 
have to deal with unsuitable employees.'

It is also of critical importance for the products of a selection process to exhibit high predictive value and usefulness considering the costs associated with the process and turnover. Pilbeam and Corbridge (2006) support this position, when they argue that inappropriate selection is very expensive. Citing a CIPD (2004) report, they assert that 'if the overall costs of leaving, including payroll and administration, recruitment and selection time and fees, induction, training, unproductive time and any other indirect loss of business or customer satisfaction, are taken into account, the estimated cost per leaver can be around $£ 5000$, and $£ 7000$ for managers and professionals' (Pilbeam \& Corbridge, 2006: 142).

A correlation coefficient is usually adopted in measuring predictive validity. Taylor (2007: 4) summarises the analysis of the coefficient correlation thus:

Were a selection process to be found to have resulted in a correlation coefficient of 1 , it would have predicted the relative performance of employees with perfect accuracy. Conversely, a correlation coefficient of score equal to 0 indicates the absence of any predictive accuracy at all- the employer might as well have picked candidates at random. see Table 1.

In all, predictive validity helps measure the utility and reliability of a selection process as a HR strategy. It makes it possible to empirically test a particular selection procedure with the performances of those selected through the process with a view of enhancing the efficacy of such method.

In spite of its overwhelming usefulness as critical concepts in the selection process, predictive and face validity have their limitations. For example, face validity, because of its peculiar nature as an individual's perception of a selection process, is very difficult -if not impossible- to measure. A process that might appear fair and face valid to one candidate might be viewed as invasive and inappropriate by another. Similarly, the problem of generalisation, measurement criteria and sampling biases, limits predictive validity (Pilbeam \& Corbridge, 2006). What is important therefore, is to understand the nature of these limitations and strive to improve on them, bearing in mind that no selection method can predict future job performance in absolute terms; and none can be completely satisfactory to all applicants. Having come to this conclusion, the pertinent question that follows is: how can these factors be maximised?

\section{Maximising the Predictive and Face Validities of the Interview, Work Sampling and Assessment Centres}

In the absence of any 'perfect' selection method that guarantees absolute predictive and face validity, employers have continued to make do with several techniques aimed at maximising the utility and reliability of the process. It is instructive to point out however, that certain selection procedures are good predictors of job performance, despite very low face validity (Ni \& Hauenstein, 1998). A recent meta-analytic data suggest that Assessment Centres tend to have the highest predictive value with a correlation coefficient $(\mathrm{r})$ of 0.7 , while such banal methods such as Graphology, Astrology and Age ranked least with a coefficient of 0 (Pilbeam \& Corbridge, 2006) - See Table 1.

What is striking however, is the fact that organisations have continued to use certain selection procedures (e.g. interviews) with seemingly less predictive validity in the face of alternatives that record higher accuracy, perhaps, because of their high face value. The next paragraphs critically examine the interview, work sampling and assessment centres as methods of employee selection and suggest ways through which their predictive and face validity can be maximised.

Table 1. Predictive validity of selection methods: a summary of correlations
1.0 Certain prediction
0.9
0.8
0.7 Assessment centres for development
0.6 Skilful and structured interview, ability test, including numerical and verbal reasoning
0.5 Work sampling
0.4 Assessment centres for job performance 
Bio data, personality assessment

0.3 Unstructured interviews

0.2

0.1 References

Interests

Years of job experience

0.0 Graphology

Astrology

Age

Source: Pilbeam \& Corbridge (2006: 173).

\subsection{The Interview}

Despite many years of intense criticisms as a poor predictor of job performance, the interview has remained astonishingly popular among many organisations, particularly in the U.K. A recent CIPD (2009) survey of 755 U.K organisations indicate that close to $70 \%$ of these organisations made use of one form of the interview or another in their employee selection process; even as only 50\% and 35\% made use of test for specific skills (work sampling) and assessment centres respectively.

Perhaps, the popularity of the interview is a product of its acceptance by all parties in the selection process, including candidates themselves, i.e. high face value (Currie, 2006). Over the years, many studies have shown several weaknesses of the traditional interview. Some of these deficiencies include: primacy effect, fundamental attribution error effect, stereotyping effect and temporal extension effect (Taylor, 2008: 268).

Given these limitations of the traditional interview and the continued propensity of employers and HR practitioners to the technique, structuring the process has been suggested as a means of improving the method and increasing its validity (Barcley, 1996). Several meta-analysis of the issue (e.g. Anderson \& Shackleton, 1993) indicate that structuring the process increases its validity and reliability. Structured interviews may be distinguished with the following features: "using job analysis to make questions relevant to the job, asking the same questions of all candidates as well as using systematic scoring procedures" (Barcley, 1996: 136).

Yet, even the structured interview, despite its higher predictive accuracy has several limitations, particularly its rigidity and the potentiality of impairing applicants' responses. Taylor (2008: 276) succinctly sums these limitations thus:

While structuring interviews...maybe a highly effective method of improving their predictive quality, it is not necessarily conducive to the creation of a relaxed atmosphere in which the candidate can easily open up. There is evidence to suggest that unless handled carefully by trained interviews, structured interviews can be unsatisfactory and the assessment of the individual can be inaccurate as a result.

To minimise these limitations and enhance the predictive validity of the structured interview, the following are recommended:

- Semi- structuring and mixed approaches to reflect a greater degree of flexibility and adaptability (Anderson \& Shackleton, 1993).

- The involvement of line managers who have a good knowledge of particular job and behaviours required for success (Barcley, 1996).

- Interview questions should be based on a 'comprehensive, accurate and up to date job description' (Taylor, 2008: 279). Propriety of questions is also important, as improper questioning and prejudiced statements may lower the face validity of the process.

- Questions should derive from a "meaningful person specification that genuinely discriminates between the 'essential' and the 'desirable' in a fashion that, at least in principle enables definitive judgements to be made (Taylor, 2008).

- Organisational context and current environment should be considered when structuring the questions (Barcley, 1996; Anderson \& Shakleton, 1993). 
- Adequate, comprehensive and well informed preparation on the part of the interviewer.

The foregoing, together with a well trained interviewer, will undoubtedly go a long way in maximizing the efficacy of not just the structured interviews, but the less structured and the more traditional forms as well.

\subsection{Work Sampling}

With regards to the face validity of specific tools, Interviews and Work Sampling have enjoyed tremendous acceptability from candidates. This perhaps, explains why several organisations are increasingly adopting work sampling as a preferred selection method (CIPD, 2009). Also referred to as specific skills tests, work sampling, 'provides opportunities for candidates to experience or simulate job tasks and for employing organisations to observe and assess candidate competencies and performance' (Pilbeam \& Corbridge, 2006: 186). This process has been shown to be very useful in terms of its predictive accuracy, recording a coefficient of 0.5 or more in some instances (Hausenectch et al, 2004).

It is instructive to point out that the efficacy of this technique is dependent on appropriate design and application. Therefore, to maximise its utility as a selection tool, the design and implementation must be conscientious and painstaking. Pilbeam and Corbridge (2006: 186) summarise the design principles for effective work sampling process to include:

- Determine the essential abilities of the job in question through discussion with job holders and line managers- competency analysis.

- Construct a work sampling activity which provides a genuine opportunity for the demonstration of critical abilities required.

- Determine the performance standards and assessment criteria, together with a mechanism for scoring individual candidate's performance.

- Train assessors, pilot the work sample, evaluate and refine.

- Develop clear, fair and consistent instructions for work sample candidates which include common advance information and briefing immediately prior to the work sampling activity.

- Locate work sampling appropriately within the recruitment and selection system, either to supplement other selection techniques or integrated within an assessment centre approach.

Yet, notwithstanding the fact that several research findings indicate that work samples can be a reliable and valid selection method, its systematic nature makes its design and implementation a very difficult and time consuming process; even as its organisational and job specificity is also a major limitation. It therefore, needs to be consistently updated to remain effective.

As a way of maximising its efficacy and validity as a selection tool, work sampling should greatly make use of simulations and pre-prepared work samples where possible; even as the method should be used together with other selection techniques (like interviews) or incorporated into an assessment centre design (Pilbeam \& Corbridge, 2006).

\subsection{Assessment Centres}

As already noted, Assessment Centres have been shown to have the highest predictive value of all selection methods. Taylor (2008: 306) describes it as the 'Rolls Royce' of selection methods. An assessment centre is an integration of several selection methods to maximise validity and reliability and not a place. As Graham and Morley (1998: 207) aptly put it:

The assessment centre is not, as its name might imply, a single unified method of predicting job performance. Essentially, an assessment centre is a structured combination of assessment techniques that are used to provide a wide-ranging, holistic assessment of each participant. However, in practice, each attribute is analysed out of the whole.

Whereas this paper does not pretend to give a comprehensive analysis of Assessment Centres for want of space, a critical examination of some of its salient and critical success factors will suffice. In this regard, just like work sampling, the design and proper implementation of the process is crucial for its effectiveness. Garavan and Morley (1998: 209) and Pilbeam and Corbridge (2006: 188) give a summary of the design of an effective assessment centre to include:

1) Proper job and competency analysis.

2) Choosing and combining assessment techniques. 
3) Assembling an integrated programme

4) Choosing and effectively training assessors

5) Selecting and preparing candidates; and

6) Post-event review and evaluation.

What is important is to be clear of what is being assessed and make well informed and strategic choice of assessment techniques (Pilbeam \& Corbridge, 2006). These techniques should be carefully chosen to test a wide-range of competencies and may involve: group exercises, in-tray exercises, role plays, simulations, interviews, personality questionnaires and other forms of psychometric testing (Garavan \& Morley, 1998).

Despite its high predictive and face validity, assessment centres have been heavily criticised for some of its test content, time duration and intensity, labour demands (availability of assessors) and most especially its prohibitive costs. It is this last factor that perhaps, explains why the process has not enjoyed outstanding popularity, especially among SMEs and smaller organisations with limited budgets. As a panacea to its prohibitive costs, this report suggests the adoption of 'mini-assessment centres' by smaller organisations that lack the financial muscle to support a fully fledged system. This way, they too can leverage on the proven predictive and face value of assessment centres (Pilbeam \& Corbridge, 2006).

To further improve on the predictive and face validity of assessment centres, the following factors are imperative:

- The techniques and exercises chosen must be shown to be job related and to describe all common and important elements of the job. Proper job and person specification is important in this regard (Garavan \& Morley, 1998).

- Complete and detailed information on all aspects of the process should be made available to candidates in due course; even as the process should accommodate the interests of the disabled and minority groups. Candidates are also entitled to an unbiased professional feedback on their performances (Pilbeam \& Corbridge, 2006).

- The process should be flexible and devoid of irrelevant physiological and psychological deprivation, ensuring that the timeframe does not drag unnecessarily (Pilbeam \& Corbridge, 2006).

- Assessors and facilitators must be well trained professionals and the process must be subjected to critical and objective evaluation through systematic feedbacks and predictive validity of those selected from the process.

From the foregoing, it is evident that an underlying factor for the success of assessment centres lay in proper design matrix (manned by competent facilitators) that inculcates the core competencies needed for the job through proper job analysis and person specification; and takes legal and ethical issues into consideration.

Technology can also be very useful in improving the face validity of these selection processes. Recruiters can "use technology to capture data about skills and capabilities of a candidate, which can then be compared against a set of skills the company has defined in the system as necessary for a vacant role', this eliminates bias and claims of discrimination (Philip, 2007: 4).

\section{Conclusion and Recommendations}

Given the attendant benefits for organisations of selection methods with high predictive validity, it is plausible to argue that maximising predictive validity in selection should be a primary pursuit of HR practitioners. While this is desirable, the recognition that selection is a two way process of organisations selecting candidates and vice versa, means that the process must also be fair, 'dealing equitably, honestly and courteously with all applicants and providing framework within which diverse candidates can demonstrate their abilities (Pilbeam \& Corbridge, 2006: 142). Indeed, in the wake of severe 'talent' and skills shortages, organisations should endeavour to maintain its attractiveness and brand appeal through its selection policies (CIPD, 2010). In this regard, Employer Branding, Realistic job preview, accurate and complete information and comprehensive job analysis and person specification prior to selection is vital (CIPD, 2009). To improve the predictive validity of the techniques examined, it seems evident that structuring the interview is a viable option. Properly designed and implemented work samples, used together with other techniques or as part of an assessment centre improves its validity; while an assessment centre's efficacy as a selection tool is dependent on its proper design matrix and implementation.

While there is no single best method of selection, a combination of carefully chosen methods, well trained HR persons and adherence to ethical and legal standards should improve face and predictive validity. Consistent with 
the competency framework in HR, in the context of selection, it seems plausible to advocate for contingency in employee selection (French \& Rumbles, 2009). Organisations must critically examine the implications of arbitrary and poor selection methods and adopt a model that is both cost efficient and effective, in line with the organisational context and culture, bearing in mind that there is no perfect selection system and that the idea of 'best practices' are sometimes misleading, because what works for company 'A', might not necessarily work for 'B'.

\section{References}

Allen, D. G., Mahto, R. V., \& Otondo, R. F. (2007). Web-based recruitment: effects of informational, organisational brand, and attitudes toward a web site on applicant attraction. Journal of Applied Psychology, 92(6), 1696-1708. http://dx.doi.org/10.1037/0021-9010.92.6.1696

Anderson, N. R., \& Shackleton, V. J. (1993). Successful selection interviewing. Oxford: Blackwell.

Balmer, J., \& Gray, E. R. (2003). Corporate brands: what are they? What of them? European Journal of Marketing, 37, 972-997. http://dx.doi.org/10.1108/03090560310477627

Barcley, J. M. (1999). Employee selection: a question of structure. Personnel Review, 28(1/2), 134-151. http://dx.doi.org/10.1108/00483489910249045

Bauer, T. N. et al. (1998). A longitudinal assessment of applicant reaction to an employment test. Journal of Applied Psychology, 83, 892-903. http://dx.doi.org/10.1037/0021-9010.83.6.892

Bauer, T. N. et al. (2001). Development of the selection procedural justice scale (SPJS). Personnel Psychology, 54, 387-419. http://dx.doi.org/10.1111/j.1744-6570.2001.tb00097.x

Chartered Institute of Personnel and Development - CIPD. (2009). Recruitment, retention and turnover. Annual Survey Report. London: CIPD.

Chartered Institute of Personnel and Development - CIPD. (2010). Labour market outlook. Quarterly Survey Report. London: CIPD.

Currie, D. (2006). Introduction to human resource management. London: CIPD.

French, R., \& Rumbles, S. (2009). Recruitment and selection. In C. Rayner \& D. Adam Smith (eds.), Managing and Leading People (pp. 139-156). London: CIPD.

Garavan, T. N., \& Morley, M. (1998). Graduate assessment centres: an empirical investigation of effectiveness. Education + Training, 40(5), 206-219. http://dx.doi.org/10.1108/00400919810220789

Gilliland, S. W. (1993). The perceived fairness of selection system: an organisational justice perspective. Academy of Management Review, 18, 694-734.

Hausknecht, J. P., Day, D. V., \& Thomas, S. C. (2004). Applicants reactions to selection procedures: An updated model and meta-analysis. Personnel Psychology, 24(March). Cornell University ILR School. http://dx.doi.org/10.1111/j.1744-6570.2004.00003.x

Jones, G. R., \& George, J. M. (2006). Contemporary management. New York: McGraw- Hill Irwin.

Kew, J., \& Stradwick, J. (2008). Business environment: managing in a strategic context. London: CIPD.

Livens, M., VamlDam, K., \& Anderson, N. (2002). Recent trends and challenges in personnel selection. Personnel Review, 32(5), 580-601. http://dx.doi.org/10.1108/00483480210438771

$\mathrm{Ni}$, Y., \& Hauenstein. (1998). Applicant reaction to personality tests: effects of item invasiveness and face validity. Journal of Business and Psychology, 12(4), 391-406. http://dx.doi.org/10.1023/A:1025010304332

Philips, C. (2007). Today's talent contest: the battle for talent in the UK is hotting up. Human Resource Management Digest, 15(3), 3-5. http://dx.doi.org/10.1108/09670730710743907

Pilbeam, S., \& Corbridge, M. (2006). People resourcing: Contemporary HRM is practice (3rd ed.). Essex England: Printice Hall.

Polyhart, R. E., \& Ryan, A. M. (1998). Applicants' reaction to the fairness of selection procedures: the effects of positive rule violations and time of measurement. Journal of Applied Psychology, 83, 3-16. http://dx.doi.org/10.1037/0021-9010.83.1.3

Raynes, S. L., Bretz Jr, R. D., \& Gerhart, B. A. (1990). The importance of recruitment in job choice: A different way of looking. Centre for Advanced Human Resource (CAHRS), Working Paper 90-24. Retrieved from 
http://digitalcommons.ilr.cornell.edu/cahrswp/389

Ryan, A. M., \& Polyhart, R. E. (2000). Applicant Perception of selection procedures and decisions: a critical review and agenda for the future. Journal of Management, 26, 565-606. http://dx.doi.org/10.1177/014920630002600308

Rynes, S. L. (1989). Recruitment, job choice, and post- hire consequences: A call for new research direction. Centre for Advanced Human Resource (CAHRS), Working Paper 89-07. Retrieved from http://digitalcommons.ilr.cornell.edu/cahrswp/398 (Draft)

Rynes, S. L. (1993). Who's selecting whom? Effects of selection practices on applicant attitudes and behaviour. In N. Schmitt \& W.C. Borman (Eds.), Personnel Selection in organisations. San Francisco: Jossy Bass. Cited in R. E. Polyhart . \& A. M. Ryan. (1998). Applicants' reaction to the fairness of selection procedures: the effects of positive rule violations and time of measurement. Journal of Applied Psychology, 83, 3-16.

Smither, J. W. et al. (1993). Applicant reaction to selection procedures. Personnel Psychology, 46, 49-76. http://dx.doi.org/10.1111/j.1744-6570.1993.tb00867.x

Spence, M. (1973). Job market signalling. Quarterly Journal of Economics, 87, 355-374. http://dx.doi.org/10.2307/1882010

Taylor, S. (2007). People resourcing (4th ed.). London: CIPD.

Ziegert, J. C., \& Ehrhart, K. H. (2004). A theoretical framework and guide for future research on applicants' attraction. Academy of Management proceeding conference paper HR: C1. Retrieved from http://www.seiofbluemountain.com/search/detail.php?id=758 